12

\title{
Прозрачные лампы бегущей волны с многоскоростными электронными пучками
}

\author{
() Ю.А. Калинин, А.В. Стародубов
}

Саратовский национальный исследовательский государственный университет им. Н.Г. Чернышевского, Саратов, Россия

ॠ E-mail: StarodubovAV@gmail.com

Поступило в Редакцию 27 февраля 2018 г.

Приведены результаты теоретического и экспериментального исследования выходных характеристик прозрачных ламп бегущей волны (без локального поглотителя) с многоскоростными (турбулентными) электронными пучками. Показано, что в этом случае достигаются более высокие коэффициенты усиления (до $20 \mathrm{~dB}$ ) и коэффициенты полезного действия $(40-50 \%)$ по сравнению с выходными характеристиками прозрачных ламп бегущей волны с моноскоростными (ламинарными) электронными пучками. Указанный эффект объясняется формированием в многоскоростном электронном пучке гораздо более плотных сгустков пространственного заряда, чем для моноскоростных электронных пучков.

DOI: $10.21883 /$ PJTF.2018.18.46612.17266

Известны лампы бегущей волны (ЛБВ), в конструкции пространства дрейфа которых отсутствует локальный поглотитель, вследствие чего такие ЛБВ называют прозрачными [1]. Указанные прозрачные ЛБВ могут работать при больших параметрах несинхронности (значения параметра несинхронности лежат в диапазоне 2.5-3.5) и высоких уровнях мощности входных сигналов [2-5], что определяет такой режим работы как крестатронный [3]. Данный режим работы характеризуется большим электронным коэффициентом полезного действия (КПД), но малым коэффициентом усиления $(8-10 \mathrm{~dB})$. Указанные приборы используются в усилительных цепочках в качестве выходного каскада (усилителя мощности) и повышают выходную мощность цепочки. Как правило, в прозрачных ЛБВ в рабочем режиме формируются интенсивные электронные пучки, близкие к ламинарным. 


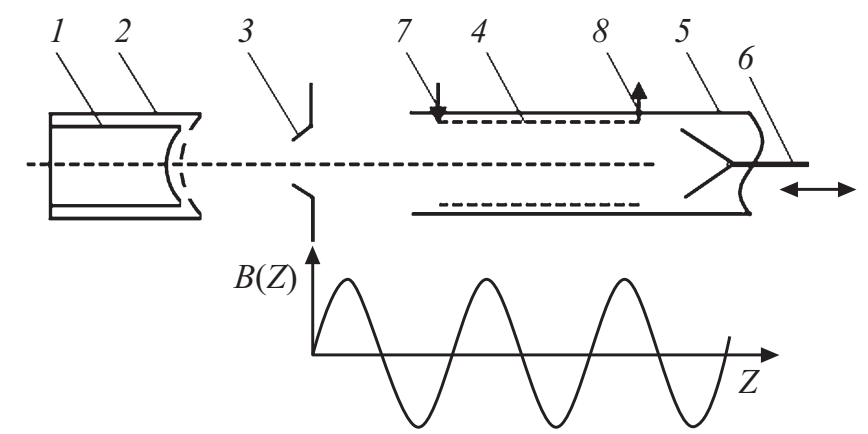

Pис. 1. Схема макета прозрачной ЛБВ с турбулентным электронным пучком и распределение периодического магнитного поля в нем. 1 - катод, $2-$ управляющий электрод, 3 - анод, 4 - замедляющая система, 5 - корпус, 6 - подвижный коллектор, 7 - ввод СВЧ-энергии, 8 - вывод СВЧ-энергии.

В настоящее время задачи оптимизации процессов взаимодействия в приборах электроники больших мощностей для получения необходимых характеристик мощного выходного СВЧ-излучения не утратили своей актуальности. Одной из центральных здесь является задача улучшения выходных характеристик источников СВЧ-излучения: повышение выходной мощности и коэффициента полезного действия, повышение частоты, расширение полосы генерируемых частот [6]. Одним из возможных решений указанных задач может быть использование многоскоростных (турбулентных) электронных пучков. Такие пучки могут найти применение в широкополосных генераторах на виртуальном катоде низковольтных виркаторах, в лампах обратной волны и т.д. [7-9]. Отличительной особенностью многоскоростных (турбулентных) пучков является наличие сверхплотных сгустков пространственного заряда, совершающих интенсивные пространственно-временны́е колебания [10]. В настоящей работе рассматривается влияние интенсивных сгустков пространственного заряда, образованных многоскоростными электронными пучками, на энергетические и спектральные характеристики усилителей СВЧ-сигнала на базе прозрачных ЛБВ.

Схема лабораторного макета прозрачной ЛБВ представлена на рис. 1. Экспериментальные исследования проводились с использованием разборной вакуумной установки [11], в рабочей камере которой 


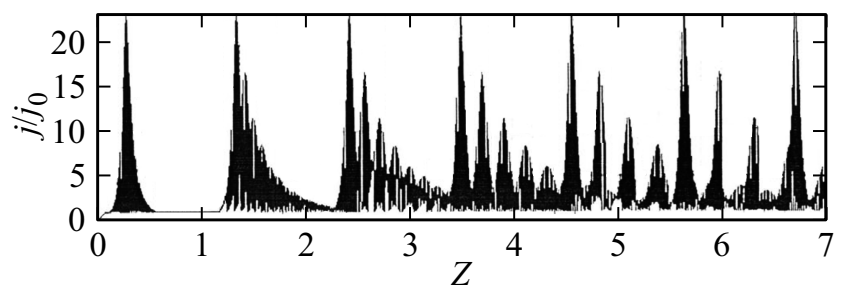

Рис. 2. Результаты численного моделирования вида распределения плотности тока $j / j_{0}$ в сгустках пространственного заряда.

осуществлялось размещение всех элементов лабораторного макета прозрачной ЛБВ. В разработанном лабораторном макете электронная пушка со сферическим катодом формирует цилиндрический пучок с током $I=500-700 \mathrm{~mA}$ при ускоряющем напряжении $U_{0}=8-10 \mathrm{kV}$ в импульсном режиме (длительность импульса $50 \mu \mathrm{s}$, скважность $Q=1000$ ). Изменение величины разброса электронов по продольным скоростям $\Delta V / V_{0}\left(\Delta V-\right.$ величина разброса скоростей, $V_{0}-$ средняя скорость электронов) проводилось путем изменения потенциала прикатодной сетки, величина которого менялась в диапазоне $U_{n} / U_{n a t}=1-3.5\left(U_{n}-\right.$ потенциал сетки, $U_{n a t}$ - естественный потенциал сетки). Изменяя таким образом потенциал сетки, можно получить величину разброca $\Delta V / V_{0} \sim 25-40 \%$. Величина разброса электронов по продольным скоростям определялась экспериментально с использованием метода тормозящего поля [10], для чего в канал пространства дрейфа помещался подвижный зонд с диафрагмой с диаметром отверстия $50 \mu \mathrm{m}$. Конструкция зондового устройства включала в себя коллектор, выполненный в виде цилиндра Фарадея, на который подавался задерживающий потенциал. В лабораторном макете использовалась спиральная замедляющая система с вводом и выводом СВЧ-энергии. Электронный пучок фокусировался с помощью магнитной периодической системы с амплитудой поля $B=0.05-0.1$ Т и периодом $d=25 \mathrm{~mm}$.

В соответствии с методикой, приведенной в [12], было выполнено численное моделирование структуры многоскоростных электронных пучков. На рис. 2 приведено распределение относительной плотности тока $j / j_{0}$ в пролетном канале $(j-$ плотность тока в пролетном канале, $j_{0}-$ плотность тока на входе в пролетный канал). Приве-

Письма в ЖТФ, 2018, том 44, вып. 18 
Результаты экспериментального исследования макета прозрачной ЛБВ

\begin{tabular}{c|c|c|c|c|c|c|c|c}
\hline $\begin{array}{r}\text { Тип } \\
\text { пучка }\end{array}$ & $\Delta V / V_{0}, \%$ & $U_{0}, \mathrm{kV}$ & $I, \mathrm{~mA}$ & $P_{i n}, \mathrm{~W}$ & $G, \mathrm{~dB}$ & $P_{\text {out }}, \mathrm{kW}$ & $\eta_{e}, \%$ & $\eta_{t}, \%$ \\
\hline 1 & 0 & 8 & 320 & 100 & 10 & 1 & 35 & 47 \\
2 & 30 & 10 & 540 & 25 & 20 & 2.5 & 46 & 63
\end{tabular}

денные результаты соответствуют величине разброса электронов по продольным скоростям $\Delta V / V_{0} \sim 30 \%$. Из рис. 2 видно, что начальный разброс электронов по скоростям приводит к образованию сгустков пространственного заряда в пролетном канале. Результаты проведенных исследований в рамках численного моделирования показали (рис. $3, a$ ), что плотность тока в сгустках пространственного заряда также существенно зависит от величины амплитуды магнитного поля и достигает величин $j / j_{0} \sim 400$ при амплитудах магнитного поля $B_{0} \sim 0.1 \mathrm{~T}$. Зависимость плотности тока в сгустках пространственного заряда $j / j_{0}$ от величины разброса электронов по продольным скоростям $\Delta V / V_{0}$ для амплитуды магнитного поля $B_{0}=0.06 \mathrm{~T}$ приведена на рис. $3, b$. Видно, что, с одной стороны, наличие разброса электронов по скоростям позволяет получать более плотные сгустки. С другой стороны, имеется оптимальное значение величины разброса электронов по скоростям, при котором наблюдаются наиболее плотные сгустки пространственного заряда.

На рис. $3, c$ и $d$, а также в таблице приведены результаты экспериментального исследования макета прозрачной ЛБВ с моноскоростным (случай 1) и многоскоростным (случай 2) электронными пучками. Все экспериментальные результаты получены в диапазоне частот $1-2 \mathrm{GHz}$. Зависимость коэффициента усиления $G$ от величины разброса скоростей $\Delta V / V_{0}$ приведена на рис. 3, $c$. Из представленного рисунка видно, что для многоскоростного (турбулентного) электронного пучка максимальное значение коэффициента усиления достигает $G=20 \mathrm{~dB}$ при $\Delta V / V_{0}=30 \%$, а для моноскоростного (ламинарного) $G=10 \mathrm{~dB}$. На рис. $3, d$ приведена зависимость электронного КПД от величины мощности входного сигнала. Видно, что максимальное значение электронного КПД для многоскоростного (турбулентного) электронного пучка достигается при $P_{i n} \sim 25 \mathrm{~W}$, а для моноскоростного

Письма в ЖТФ, 2018, том 44, вып. 18 


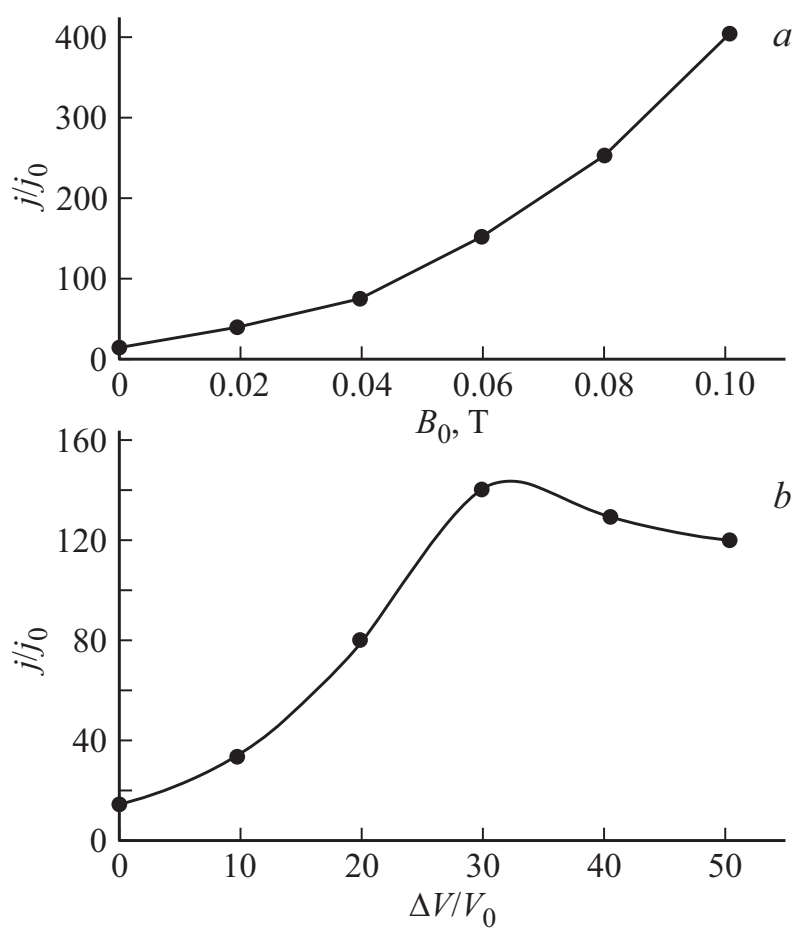

Рис. 3. Результаты численного моделирования $(a, b)$ и экспериментальных исследований $(c, d) . a-$ зависимость относительной плотности тока $j / j_{0}$ от амплитуды магнитного поля $B_{0}$, полученная при численном моделировании; $b$ - зависимость относительной плотности тока $j / j_{0}$ от величины разброса электронов по продольным скоростям $\Delta V / V_{0}$, полученная при численном моделировании; $c$ - экспериментально полученная зависимость коэффициента усиления $G$ от величины разброса электронов по продольным скоростям $\Delta V / V_{0}$; $d$ - экспериментально полученная зависимость электронного КПД $\eta_{e}$ от величины входного сигнала $P_{i n}: 1-$ прозрачная ЛБВ с ламинарным пучком, 2 - прозрачная ЛБВ с турбулентным пучком.

(ламинарного) электронного пучка - при $P_{\text {in }} \sim 100 \mathrm{~W}$. Результаты экспериментального исследования обобщены в таблице.

Таким образом, в рамках данной работы проведено теоретическое и экспериментальное исследование влияния многоскоростного (турбу-

Письма в ЖТФ, 2018, том 44, вып. 18 

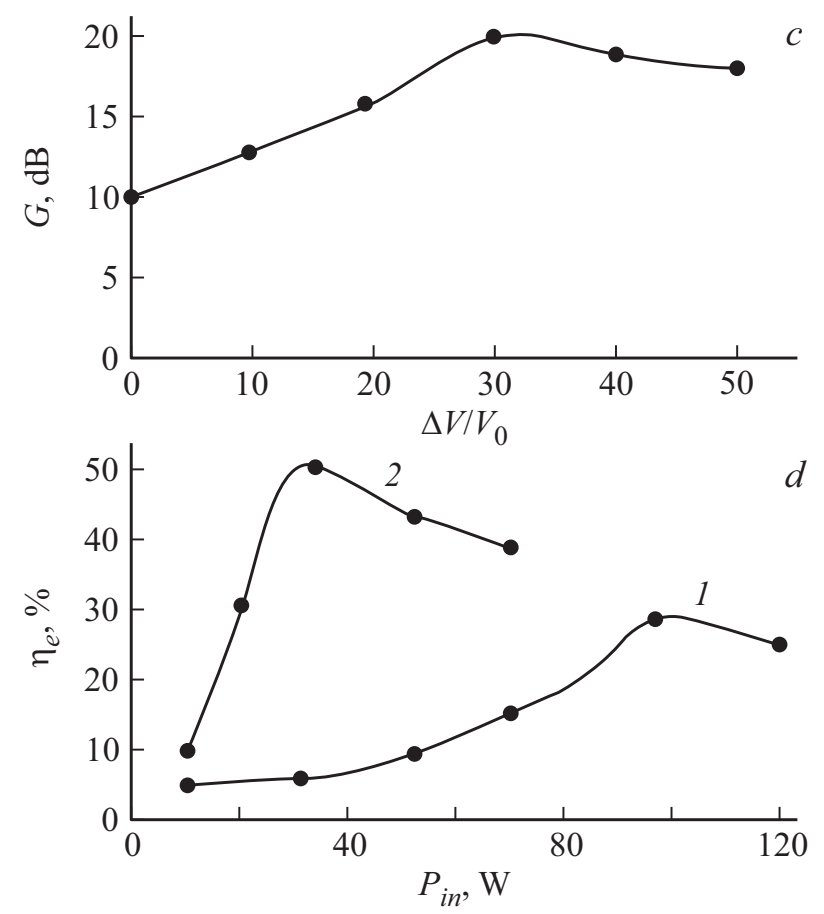

Рис. 3 (продолжение).

лентного) электронного пучка на характеристики ЛБВ без локального поглотителя (прозрачная ЛБВ). Анализ полученных результатов показал следующее.

1. Применение многоскоростного (турбулентного) электронного пучка с интенсивными сгустками пространственного заряда в статическом режиме позволяет существенно улучшить выходные характеристики прозрачных ЛБВ.

2. Имеется оптимальное значение величины разброса электронов по скоростям, при котором достигаются наибольшие плотности тока в сгустках пространственного заряда, что ведет к получению максимальных значений величины коэффициента усиления и выходной мощности исследуемой прозрачной ЛБВ.

Письма в ЖТФ, 2018, том 44, вып. 18 
3. Применение многоскоростных электронных пучков в прозрачных ЛБВ позволяет достигать коэффициента усиления $20 \mathrm{~dB}$ при электронном КПД $\eta_{e} \sim 40-50 \%$ и техническом КПД $\eta_{t} \sim 60 \%$.

Авторы выражают благодарность А.С. Фокину за помощь в подготовке и оформлении работы.

Работа выполнена при поддержке гранта РФФИ № 16-02-00238, а также Министерства образования и науки РФ в рамках проектной части госзадания (проект № 3.859.2017/4.6).

\section{Список литературы}

[1] Калинин Ю.А., Фокин А.С., Стародубов А.В. // Письма в ЖТФ. 2014. Т. 40. B. 18. C. $32-37$.

[2] Калинин Ю.А., Кач А.М., Песин Б.В. // Электронная техника. Сер. 1. Электроника СВЧ. 1973. В. 6. С. 52-59.

[3] Rowe J.E. // Proc. IRE. 1959. V. 47. N 4. P. 536-545.

[4] Калинин Ю.А., Каи, А.М. // Изв. вузов. Радиоэлектроника. 1980. Т. 23. № 10. C. $36-39$.

[5] Закурдаев А.Д., Победоносиев А.С. Многолучевой СВЧ-прибор. Патент РФ № 2054733 от 20.02.1996.

[6] Benford J., Swegle J.A., Schamiloglu E. High power microwaves. Boca Raton: CRC Press, 2007. 552 p.

[7] Стародубов А.В., Калинин Ю.А. // ЖТФ. 2013. Т. 83. В. 10. С. 108-112.

[8] Калинин Ю.А., Стародубов А.В., Волкова Л.Н. // Письма в ЖТФ. 2010. T. 36. B. 19 C. $52-58$.

[9] Абанасьев В.М., Лукин К.А., Ракитлнский В.А. // Радиофизика и электроника. 1997. Т. 2. № 1. С. 115-118.

[10] Калинин Ю.А., Стародубов А.В. // ЖТФ. 2010. Т. 80. В. 12. С. 80-85.

[11] Калинин Ю.А., Ессин А.Д. Методы и средства физического эксперимента в вакуумной СВЧ-электронике. Саратов: Изд-во Саратов. ун-та, 1991. 212 с.

[12] Molokovsky S.I., Sushkov A.D. Intense electron and ion beams. Berlin-Heidelberg: Springer-Verlag, 2005. 281 p.

Письма в ЖТФ, 2018, том 44, вып. 18 